\title{
THE ACTIVITY AND DIVERSITY OF GROUND ARTHROPODS IN AN AGROFORESTRY SYSTEM
}

\author{
R.K. PENG ${ }^{1}$ and S.L. SUTTON \\ Department of Pure and Applied Biology, University of Leeds, Leeds LS2 9JT, UK \\ ${ }^{I}$ Present address: School of Biological Sciences, Northern Territory University, \\ Darwin 0909, NT Australia
}

\begin{abstract}
Comparison of the activity and diversity of ground arthropods in an agroforestry system in northern England was made using pitfall traps. The system consisted of production hedges of timber trees (ash, cherry, sycamore and walnut) interspersed with hazel bushes, arable alleys between the hedges and control areas. The most common taxa were more active during their abundant periods in the arable alley than in the adjoining control area containing the same arable pea crop. The diversity of ground arthropods was generally higher in the arable alley than in the control area. The production hedges could play a very important part in maintaining and enriching populations of polyphagous predators close to an adjacent arable crop.
\end{abstract}

Keywords: agroforestry, diversity, arthropods, Carabidae

\section{INTRODUCTION}

A production system containing trees in addition to a herbaceous layer is likely to have more insect species and individuals associated with it than a monocultural herbaceous layer (Strong et al. 1984). Increasing intra-crop diversity by intercropping or mixed cropping of two or more crops may cause decreases in numbers of pests (Risch et al. 1983). Hedgerows, field boundaries and grassed banks, with their great diversity of flora, can play an important role in providing overwintering refuges for many species of polyphagous predators in monocultural arable systems (Thomas et al. 1991).

An agroforestry experiment has been in place since 1987 at the Leeds University Farm in West Yorkshire, UK, examining ways of increasing floral diversity in monocultural arable land. It would be expected that the agroforestry system would increase the species diversity of arthropod fauna through the provision of more food and shelter than would be found on monocultural arable fields. Furthermore, agroforestry areas should provide habitats in which natural enemies of crop pests can shelter and overwinter especially after the crops have been harvested. The analysis of aerial samples from yellow water-pan traps in 1990 has supported this hypothesis (Peng et al. 1993). This work examines (1) whether an agroforestry area can increase the activity of ground arthropods and (2) whether an agroforestry area can enhance the diversity of ground arthropods.

\section{MATERIALS AND METHODS}

The study site at Leeds University, UK, has been described in detail elsewhere (Peng et al. 1993). Briefly, the agroforestry experiment consisted of four replicate blocks, each of $10,000 \mathrm{~m}^{2}$ with four species of furniture timber trees (ash, cherry, sycamore and walnut) interspersed with hazel bushes and planted in rows (production hedge) $14 \mathrm{~m}$ apart. The arable alleys between the production hedges were sown with strips of arable crop $12 \mathrm{~m}$ wide. The production hedge trees, which were planted in 1987, were 2.5-3 m high at the time of this study in 1990. The control areas had similar exposure to prevailing winds and similar soil type to agroforestry experimental areas, 
but were 20-30 m away from them (Peng et al. 1993). The arable alleys between the production hedges and the arable control areas were sown with a pea crop (Pisum sativum L. cv. Solara) in mid-March 1990 and harvested in a dry state for animal feed in mid-August.

The activity of ground arthropods was monitored from April to August 1990 with pitfall traps. Each trap was a translucent plastic cup (diameter at the top measured 73 $\mathrm{mm}$ and $56 \mathrm{~mm}$ at the bottom with a height of $107 \mathrm{~mm}$ ) with its top flush with the ground. A $77 \mathrm{~mm}$ diameter plastic cylinder supported the cup, prevented soil from falling into the hole in the ground and facilitated removal of the cup for emptying. Each trap was kept in the same place throughout the cropping season and contained $60 \mathrm{ml}$ of ethylene glycol with a few drops of detergent when it was open for trapping.

Samples were taken from all four blocks. In each block, eight traps were positioned in the arable alleys $3 \mathrm{~m}$ from the production hedges, and eight were positioned in the control areas. Traps were emptied four times and the trapping period at each time varied: 25 April - 24 May (29 days); 24 May - 20 June (27 days); 5-19 July (14 days) and 2-10 August (8 days) just before the crop was harvested. All the insects caught in each trap were preserved in $70 \%$ ethanol and later sorted to species and family. Staphylinids were ignored because some of them were lost when the samples were sorted. The log-series index (a ) (Fisher et al. 1943) was used for the analysis of diversity: $\mathrm{S}=$ aln $(1+\mathrm{N} / \mathrm{a})$, where $\mathrm{S}=$ number of taxa and $\mathrm{N}=$ number of individuals. The greater the value of a, the more diverse is the community.

Data for all taxa and their total numbers caught in each of four blocks were analysed individually for each sampling period using paired samples t test. In each sampling period, the values of least significant difference $(5 \%)$ were also calculated. The microclimatic data were taken from the records of the meteorological station of the University Farm.

\section{RESULTS}

Individuals caught in the four sampling periods $(n=20,041)$ fell within 36 taxa. Fifteen taxa were numerically large enough to allow further analysis. Nine taxa were significantly more numerous in the arable alley than in the control area $(\mathrm{P}<0.05)$ in the periods of abundance (taxa $1-8,14$; Fig.1), five taxa were present in similar numbers in the arable alley and the control area (taxa 9 - 12, 15; Fig. 1) and taxon 13 was present in similar numbers in sampling periods 1 and 2 but more numerous in the arable alley than in the control area $(\mathrm{P}<0.05)$ in sampling periods 3 and 4 . During the periods of abundance of each taxon, 9 out of 14 predatory taxa were more numerous in the arable alley than the control area (taxa 1- 8, 14; Fig. 1). The pea weevil, Sitona lineatus, was equally distributed between the treatments in each sampling period (taxon 15; Fig. 1).

The diversity of ground arthropods between treatments over the four blocks was compared for each sampling period (Fig. 2). The diversity in the arable alley was significantly higher than in the control area $(\mathrm{P}<0.05)$ in sampling periods 1 and 4 . In sampling periods 2 and 3 , the mean diversities in the arable alley were higher than in the control area, but differences were not significant (Fig. 2). Paired samples t test to the four blocks of all the four sampling periods suggested that the arable alley contained a greater diversity of ground arthropods than the control area $(\mathrm{t}=3.90, \mathrm{P}=0.001)$.

\section{DISCUSSION}

The trapping periods in April-May, May-June, July and August were 29, 27, 14 and 8 days, respectively. Total rainfall for these periods was $17,37.7,8.7$ and $0.9 \mathrm{~mm}$ respectively, but no traps were flooded. Although the solutions of ethylene glycol in the traps were certainly diluted, this should have affected the catches equally for all the traps.

The diversity of ground arthropods was generally higher in arable alleys than in controls (Fig. 2). This agrees with analysis of air-borne arthropods (Peng et al. 1993). As the control areas have similar exposure to prevailing winds and similar soil type to the agroforestry areas, the differences in diversity between treatments cannot be 

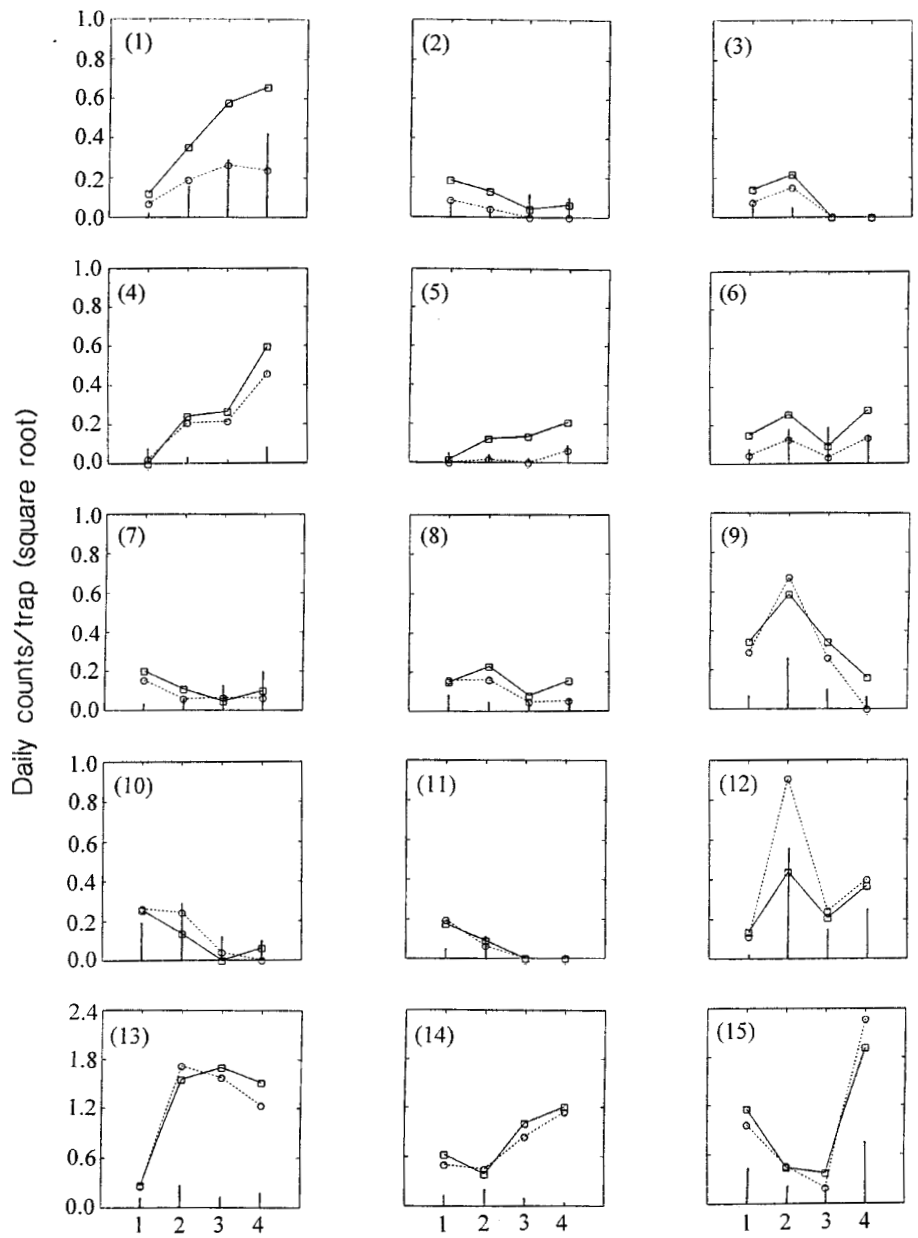

Sampling period

FIGURE 1: Daily counts of individuals of ground arthropods caught in each trap between arable alleys (solid line with open squares) and control areas (dotted line with open circles) for each taxon from April to August 1990. The vertical bar for each sampling period is the least significant difference $(5 \%)$ between the arable alley and the control area. Sampling periods: 1) 25 April - 24 May, 2) 24 May - 20 June, $3) 5$ - 19 July and 4) 2 - 10 August. Taxa: 1) Harpalus rufipes, 2 ) $H$. affinis, 3) Nebria brevicollis, 4) Pterostichus niger, 5) P. madidus, 6) Phalangium opilio, 7) Lycosidae, 8)Coccinella punctata, 9)Agonum dorsale, 10) Bembidion lampros, 11) Notiophilus biguttatus, 12) Trechus quadristriatus, 13)Pterostichus melanarius, 14) Linyphiidae and 15) Sitona lineatus. Taxa 1, 3, 8-11, 13 and 14 are able to prey on cereal aphids (Sunderland and Vickerman 1980). 


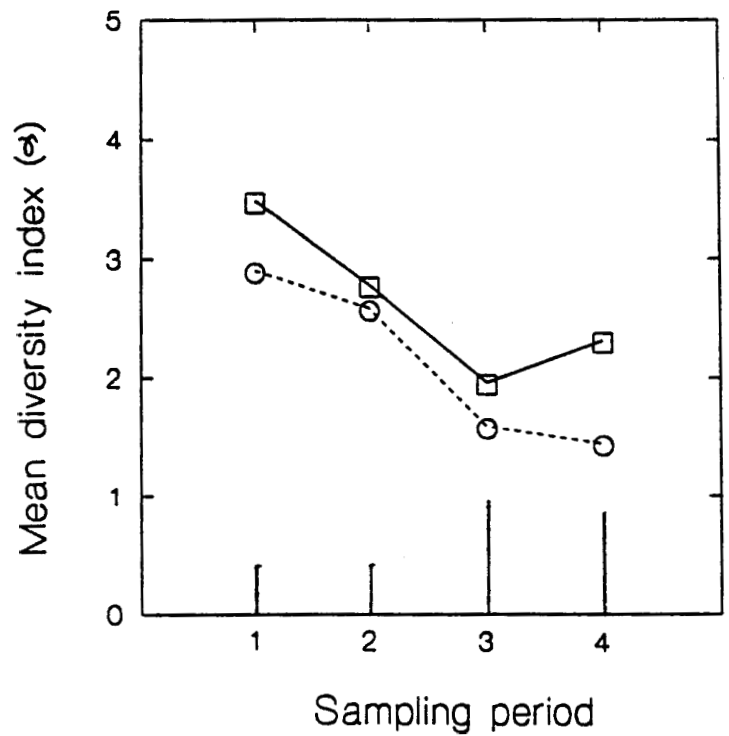

FIGURE 2: The average diversity (log series index) of ground arthropods in the arable alley (solid line) and the control area (dotted line) for each sampling period. The vertical bar for each sampling period is the LSD (5\%). Sampling periods are described in Fig. 1.

related to such physical factors. The number of plant species and plant architecture may be responsible for this difference. In the agroforestry area of each block, apart from the pea crop, seven species of trees and a number of species of plants under the trees should provide favourable overwintering sites, shelter, and a variety of food, all of which are very important for many species of polyphagous predators (Thomas et al. 1991). When compared with the control area, the production hedges and outer windbreaks of each agroforestry area should reduce the wind speed and increase the temperature in the agroforestry area (Peng 1991), which can increase ground arthropod activity (Jones 1976).

Many groups of natural enemies interact with hedgerows, field boundaries and grass banks. These habitats provide overwintering cover for Carabidae and Staphylinidae (Sotherton 1985; Thomas et al. 1991), Araneae (Edgar and Loenen 1974; Thomas et al. 1991) and Coccinellidae (Hodek 1973). In this study, arable alleys contained higher numbers of predatory species than control areas (Taxa 1-8, 13-14; Fig. 1). In addition, 14 out of 36 taxa were able to prey on cereal aphids. Of the 14, eight taxa were numerous. Of the eight, four taxa were more numerous in the arable alley than in the control area (Taxa 1, 3, 8 and 14; Fig. 1). Pterostichus melanarius and Trechus quadristriatus are open-field species and were less abundant in field boundaries than in the open crop (Jones 1976; Sotherton 1985). However, in this study, P. melanarius was found in equivalent numbers in the arable alley and the arable control area in the first two sampling periods, but was significantly more numerous in the arable alley than in the control area in the sampling periods 3 and 4 (taxon 13; Fig. 1). Similar numbers of T. quadristriatus were caught in the arable alley and the control area (taxon 12; Fig. 1). This suggests that production hedges, rather than ordinary field boundaries, can maintain high numbers of beneficial predators which could reduce aphid populations in the arable alleys over the pea growing season. 


\section{ACKNOWLEDGEMENTS}

We thank D. T. Corry for establishing and maintaining the agroforestry system. The sampling work was done by C. Wright. The research was supported by grants awarded to L.D. Incoll from the Yorkshire Agricultural Society, the Leeds Philosophical \& Literary Society and the Department of Pure and Applied Biology of Leeds University.

\section{REFERENCES}

Edgar, W.D. and Loenen, M., 1974. Aspects of the overwintering habitat of the wolf spider Paradosa lugubris. J. Zool. 172: 383-388.

Fisher, R.A., Corbet, A.S. and Williams, C.B., 1943. The relation between the number of species and the number of individuals in a random sample of an animal population. J. Anim. Ecol. 12: 42-58.

Hodek, I., 1973. Biology of Coccinellidae. Academia, Prague.

Jones, M.G., 1976. The carabid and staphylinid fauna of winter wheat and fallow on a clay with flinty soil. J. Appl. Ecol. 13:775-791.

Peng, R.K., 1991. The influence of microclimate on the spatial distribution of flying insects. Ph D Thesis, The University of Leeds, UK.

Peng, R.K., Incoll, L.D., Sutton, S.L., Wright, C. and Chadwick, A., 1993. Diversity of air-borne arthropods in a silvoarable agroforestry system. J. Appl. Ecol. 30: 551-562.

Risch, S.J., Andow, D. and Altieri, M.A., 1983. Agroecosystem diversity and pest control: data, tentative conclusions and new research directions. Environ. Ent. 12: 625-629.

Sotherton, N.W., 1985. The distribution and abundance of predatory arthropods overwintering in field boundaries. Ann. Appl. Biol. 106:17-21.

Strong, D., Lawton, J.H. and Southwood, T.R.E., 1984. Insects on Plants: community patterns and mechanisms. Blackwell Scientific Publications, Oxford.

Sunderland, K.D. and Vickerman, G.P., 1980. Aphid feeding by some polyphagous predators in relation to aphid density in cereal fields. J. Appl. Ecol. 17:389-396.

Thomas, M.B., Wrattern, S.D and Sotherton, N.W., 1991. Creation of 'Island' habitats in farmland to manipulate populations of beneficial arthropods: predator densities and emigration. J. Appl. Ecol. 28:906-917. 